\title{
INTELLIGENT ANALYZER FOR UNATTENDED OBJECT DETECTION
}

Rutuja Y. Khadse *1, Dr. S. S. Lokhande ${ }^{2}$, Prof. S. A. Koti ${ }^{3}$

${ }^{*}$ Dept. of Electronics, Sinhgad College of Engineering, Pune, Maharashtra, INDIA

${ }^{2}$ Dept. of Electronics, Sinhgad College of Engineering, Pune, Maharashtra, INDIA

${ }^{3}$ Dept. of Electronics, Sinhgad College of Engineering, Pune, Maharashtra, INDIA

\section{Abstract:}

In recent year's surveillance system have become more popular in the field of computer vision. An object which is left at a particular place under surveillance and unattended over a period of time is called unattended object. Places like airports, railway stations, big shopping malls etc. where there is potentially high security threat detecting unattended object is a very important. The main aim of project is to develop intelligent vision based analyser based on MATLAB using Image processing for unattended object detection. The detection is based on a simple mathematical model and works efficiently. The pre-processing involves a dual-time background subtraction algorithm which dynamically updates two sets of background, one after a very short interval and the other after a relatively longer duration. The framework of the proposed algorithm is based on the Approximate Median model.

Keywords:

Video Surveillance System, CCTV, Unattended Object, Object detection, Background subtraction

Cite This Article: Rutuja Y. Khadse, Dr. S. S. Lokhande, and Prof. S. A. Koti, "INTELLIGENT ANALYZER FOR UNATTENDED OBJECT DETECTION" International Journal of Research - Granthaalayah, Vol. 3, No. 6(2015): 93-99. DOI: 10.29121/granthaalayah.v3.i6.2015.3004.

\section{INTRODUCTION}

Video surveillance system is being used by human since last two decades for maintaining the security at all possible level. In early phases of video surveillance system the video captured by the cameras would simply be displayed on the screen present in the control room. The displayed video is continuously monitored by human recourse for any abnormal activities. It has been observed that there is huge increase in terrorist attacks on public places recently. Train stations, bus stations, airport, subways, shopping malls, markets are the most targeted areas of these attacks. Even the CCTV surveillance systems are present in these areas, but the analysis of footages that has been captured by these $\mathrm{CCTV}^{\mathrm{ee}} \mathrm{s}$, are rarely observed by humans. Recent studies explore and analyse the limitations or effectiveness of human being in analysing and processing the footages particularly of crowded scenes in surveillance system consisting of many cameras.

Automatic video surveillance is becoming increasingly important in many applications, including traffic control, urban surveillance, home security and healthcare. With the innovation of intelligent cameras having greater processing capabilities it is possible to design the system that can detect the suspicious behaviours and abandoned objects. There are many algorithms 


\section{INTERNATIONAL JOURNAL of RESEARCH -GRANTHAALAYAH

suggested by many researchers to handle the problem human tracking and abandoned object detection. In practice many of these algorithms are based on complex mathematical manipulation to solve simple problems, because of this many of these algorithms failed to perform adequately. This work presents a system based on a simplistic and instinctive mathematical model that works efficiently with standard input which is the industry standard for most CCTV cameras. The proposed work consists of a dual background subtraction technique which is based on Approximate Median model framework. Algorithms for tracking abandoned objects with or without occlusion are also proposed.

Many algorithms and techniques were suggested by many researcher, scientists to design Abandoned Object detection System. But most of them are practically more complex and more expensive to implement. Some uses physical components such as highly expensive filters, lasers, sonic waves etc. it is not possible to install all those cause the cost factor. The proposed System is simple and effective. It avoids the Use of above expensive physical components. It simply works on Dual background segmentation scheme. It is highly immune to various lightning conditions

\subsection{OBJECT DETECTION}

Object detection is a computer technology related to computer vision and image processing that deals with detecting instances of semantic objects of a certain class (such as humans, buildings, or cars) in digital images and videos. Well-researched domains of object detection include face detection and Abandoned Object detection from CCTV system. Object detection has applications in many areas of computer vision, including image retrieval and video Surveillance.

\subsection{WHAT IS UNATTENDED OBJECT?}

In dictionaries an unattended object is defined as the object which left back by someone with evil intention. Here we consider unattended object as object which remains stationary or inactive for some predefined time interval. This time interval is varies as per the need of surrounding. The CCTV observer or controller have rights to modify the threshold value.

\section{RELATED WORK}

Table 1: Literature Review

\begin{tabular}{|l|l|l|l|l|l|}
\hline Author & Year & Methodology & Result & Merits & Limitations \\
\hline
\end{tabular}




\section{INTERNATIONAL JOURNAL of RESEARCH -GRANTHAALAYAH \\ A knowledge Repository}

Science

\begin{tabular}{|c|c|c|c|c|c|c|}
\hline 1 & $\begin{array}{l}\text { Miguel } \\
\text { et al[1] }\end{array}$ & 2008 & $\begin{array}{l}\text { based on the } \\
\text { fusion } \\
\text { evidence } \\
\text { provided } \\
\text { three simple } \\
\text { Detectors. }\end{array}$ & $\begin{array}{l}85.2 \% \\
\text { success } \\
\text { rate }\end{array}$ & $\begin{array}{l}\text { proposed scheme is } \\
\text { significantly more } \\
\text { efficient and stable } \\
\text { Than the independent } \\
\text { detectors applied on } \\
\text { their own. }\end{array}$ & $\begin{array}{l}\text { The main } \\
\text { problem in } \\
\text { the detection of } \\
\text { this type of event } \\
\text { is the stationary } \\
\text { object } \\
\text { Extraction/detect } \\
\text { ion. }\end{array}$ \\
\hline 2 & $\begin{array}{l}\text { Tian } \\
\text { et al[2] }\end{array}$ & 2009 & $\begin{array}{l}\text { Multi-Gaussian } \\
\text { Adaptive } \\
\text { Background } \\
\text { Models with } \\
\text { complement of } \\
\text { tracking to } \\
\text { reduce false } \\
\text { positives }\end{array}$ & $\begin{array}{l}92 \% \\
\text { success } \\
\text { rate }\end{array}$ & $\begin{array}{l}\text { robustly and } \\
\text { efficiently detect } \\
\text { abandoned and } \\
\text { removed objects in } \\
\text { complex } \\
\text { Environments } \\
\text { real-time for } \\
\text { surveillance. }\end{array}$ & $\begin{array}{l}\text { Quick lighting } \\
\text { changes cause } \\
\text { problems to } \\
\text { detect } \\
\text { Abandoned or } \\
\text { removed objects. }\end{array}$ \\
\hline 3 & $\begin{array}{c}\text { Ferrando } \\
\text { et al[4] }\end{array}$ & 2006 & $\begin{array}{l}\text { Use MOG for } \\
\text { background } \\
\text { modeling }\end{array}$ & $\begin{array}{l}80 \% \\
\text { accuracy }\end{array}$ & $\begin{array}{l}\text { Very appealing } \\
\text { to its } \\
\text { computational } \\
\text { complexity. } \\
\text { easy to } \\
\text { noninvasive } \\
\text { inexpensive. }\end{array}$ & $\begin{array}{l}\text { It is very } \\
\text { difficult to detect } \\
\text { the abandoned } \\
\text { objet in the } \\
\text { Crowded area. }\end{array}$ \\
\hline 4 & $\begin{array}{l}\text { Thi Thi } \\
\text { Zin } \\
{[5]}\end{array}$ & 2011 & $\begin{array}{l}\text { Periodic } \\
\text { background } \\
\text { modeling } \\
\text { combined with } \\
\text { stochastic } \\
\text { image }\end{array}$ & $\begin{array}{l}95 \% \\
\text { accuracy }\end{array}$ & $\begin{array}{l}\text { computational } \\
\text { Effort is kept low and } \\
\text { no training steps are } \\
\text { required. }\end{array}$ & $\begin{array}{l}\text { It required to } \\
\text { maintain three } \\
\text { background }\end{array}$ \\
\hline
\end{tabular}

\section{PROPOSED WORK}

This section presents an overview of proposed unattended object analyzer. Overall design of the proposed system is as shown figure 3.1. It consists of few modules connected, that describe the operational flow of the system. Every module is designed in modular method, it helps to easily modify respective module. 


\section{INTERNATIONAL JOURNAL of RESEARCH -GRANTHAALAYAH \\ A knowledge Repository}

Science

Data extraction; in this module important information about video is fetched. It includes video length, video type, frame rate, frame length, frame Height. Data conversion; in this module the video is converted into the frames. Frame is a simply image. Not every frame is selected but some about every 0.6 second is selected. This frame is initiated to background image and buffer background image. The images are stored in form of matrix with position and intensity of that pixel. Background Segmentation Module; This Module is actual processing module. In this module the processing on the set of matrices is done. The binary image is generated by subtracting current image from background. As we are interested in all pixels that are remains stationary for some time; period binary image provide set of all stationary pixels. This pixels may or may not be part of abandoned object. This will be checked in next Module Blob analysis. Blob Detection and Analysis; Blob is a rectangle shaped set of pixels. The blobs have some properties such as centroid, the height and left value of top \& leftmost pixel Area. Blobs are considered as feasible solution for unattended Object. Blob detection simply detects all objects. Unattended Object Detection; Unattended object detection block simply put abandoned object in picture. It works with timer to process all detected blobs from previous unit. It checks time of particular blob for which it is stable. If it is grater or equal to value defined by user, blob is highlighted.

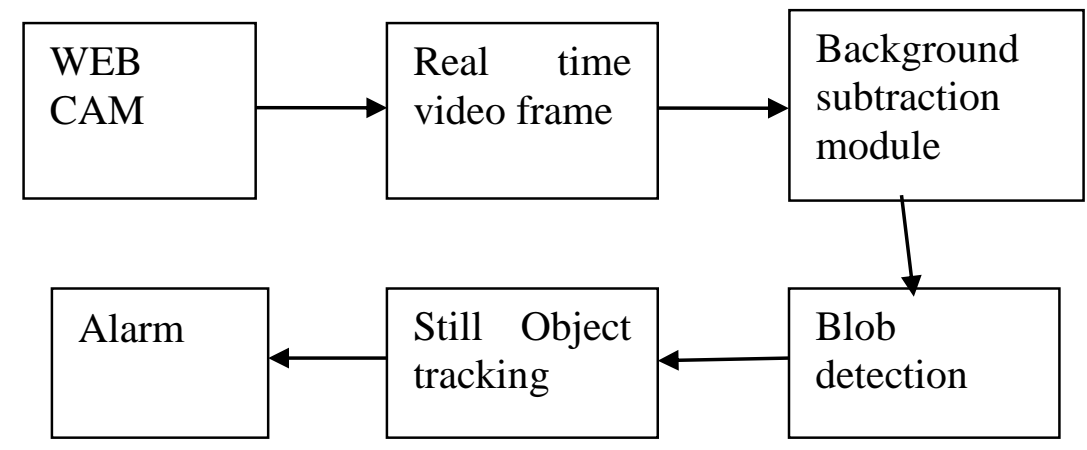

Figure 1: Block Diagram

\section{METHODOLOGY}

\subsection{OBJECT DETECTION USING APPROXIMATE MEDIAN FILTERING}

Median filtering has been shown to be very robust and to have performance comparable to higher complexity methods. However, storing and processing many frames of video (as is often required to track slower moving objects) requires an often prohibitively large amount of memory. This can be alleviated somewhat by storing and processing frames at a rate lower than 


\section{INTERNATIONAL JOURNAL of RESEARCH -GRANTHAALAYAH

the frame rate, thereby lowering storage and computation requirements at the expense of a slower adapting background. In median filtering the previous $\mathrm{N}$ frames of the video are buffered, and the background is calculated as the median of buffered frames [8], [9]. If a pixel in the current frame has a value larger than the corresponding background pixel, the background pixel is incremented by 1.Likewise, if the current pixel is less than the background pixel, the background is decremented by one. In this way, the background eventually converges to an estimate where half the input pixels are greater than the background, and half are less than the background approximately the median.

\subsection{BACKGROUND SUBTRACTION}

The background image can be calculated by subtracting the current frame from the previous frame or from the average image of a number of frames. It only works well in particular conditions of object speed and frame rate and is very sensitive to the threshold.

According to this scheme, pixels belongs to foreground if

$$
\left|I_{i}(x, y)-I_{i-1}(x, y)\right|>T
$$

Where $I_{i}$ is the current frame, $I_{i-1}$ is the previous frame and $\mathrm{T}$ is a chosen threshold.

The median/average method uses the average or the median of the previous $n$ frames As the background image, B. It is quick but very memory consuming. The required Memory is $\mathrm{n} \times \operatorname{size}($ frame).

The running average can be calculated as follows:

$$
B_{i}=\alpha I_{i-1}(x, y)-(1-\alpha) B_{i-1}(x, y)
$$

Where $\alpha$ is the adapt or learning rate (usually chosen as 0.05 ).

The running average can be expanded to accommodate selectivity, as follows:

$$
\begin{aligned}
& B_{i}=\alpha I_{i-1}(x, y)-(1-\alpha) B_{i-1}(x, y) \quad \text { if is } I_{i-1}(x, y) \text { background, } \\
= & B_{i-1}(x, y) \quad \text { if is } I_{i-1}(x, y) \text { foreground }
\end{aligned}
$$

\section{BLOB DETECTION}

Binary image is provided as an input to an algorithm one which described and returns various properties of the detected blobs as bounding box, area, centered place etc. A simplified version of the algorithm is as follows:

1. Discover and create a region counter.

2. An image is scanned from all four directions, from left to right and from top to bottom.

3. Check for every pixel the north and west pixel (4-connectivity) or the northeast, north, northwest, and west pixel (8-connectivity) to find out intensity value of 1 in the binary image (termed as criterion of blob analysis).

4. If the neighboring pixel intensity is not fitting into the criterion assign a value to region counter. Increment the region counter.

5. When any one neighboring pixel fits into the criterion, that pixel is assigned to that region. 


\section{INTERNATIONAL JOURNAL of RESEARCH -GRANTHAALAYAH \\ A knowledge Repository}

Science

6. With multiple regions, if more than one neighbor matches the criterion of the same region then assign pixel to their respective region.

7. If the members from different regions match the criterion, assign those to any one of region amongst present and notify those of that region and are equivalent.

8. Image is scanned again and the same value is assigned to all the regions those are equivalent.

\section{CONCLUSION}

This Proposed work helps for security of hospitals, museums under video surveillance, system based on a dual background segmentation scheme. Blob analysis is done on the segmented background and a dynamic tracking algorithm is devised for tracking the blobs. Proposed workis simple and computationally less intensive as it avoid the use of expensive filters while achieving better detection results. Still the research is going on in the detection techniques.

\section{ACKNOWLEDGEMENTS}

I would like to the express my true sense and a sincerest gratitude to my guide Dr. S. S. Lokhande \& Prof. S. A. Koti for their dynamic and valuable guidance. I am grateful to them for constant encouragement in the fulfillment of the seminar work. This work is a result of combined efforts put in by my guide and me. I would also like to thank them for providing me with all necessary infrastructure and facilities to complete the project.

\section{REFERENCES}

[1] Y. Cho, S.O. Lim, H.S. Yang, "Collaborative occupancy reasoning in visual sensor network for scalable smart video surveillance," IEEE Trans. On Consumer Electronics, vol. 56, no. 3, pp. 1997-2003, Aug. 2010.

[2] Xuli Li, Chao Zhang, Duo Zhang, "Abandoned Objects Detection Using Double Illumination Invariant Foreground Masks”, 2010 International Conference on Pattern Recognition

[3] Ying-li Tian, Rogerio Feris, Arun Hampapur, "Robust Detection of Abandoned and Removed Objects in Complex Surveillance Videos”, IEEE Transactions on Systems, Man, and Cybernetics, 2010

[4] Jianting,Wen,Haifeng Gong, Xia Zhang and Wenze Hu, "Generative Model For Abandoned Object Detection”, IEEE International Conference on Image Processing, 2009

[5] Chi-Hung Chuang, Jun-Wei Hsieh, Luo-Wei Tsai, Sin-Yu Chen, and Kuo-Chin Fan, Carried Object Detection Using Ratio Histogram and its Application to Suspicious Event Analysis, IEEE transactions on circuits and systems for video technology, vol. 19, NO. 6, JUNE 2009. 


\section{INTERNATIONAL JOURNAL of RESEARCH -GRANTHAALAYAH

Science

[6] W. Lao, J. Han, P.H.N. de With, "Automatic video-based human motion analyzer for consumer surveillance system," IEEE Trans. on Consumer Electronics, vol. 55, no. :2, pp. 591-598, May 2009.

[7] Chuan-Yu Cho, Wei-Hao Tung and Jia-Shung Wang, "A Crowd-Filter For Detection Of Abandoned Objects In Crowded Area”, $3^{\text {rd }}$ International Conference on Sensing Technology, Nov. 30 - Dec. 3,2008, Tainan, Taiwan

[8] T. B. Moeslund, A. Hilton, and V. Kruger, "A survey of advances in vision-based human motion capture and analysis," Computer Vision and Image Understanding, vol. 104, pp. 90-126, 2006.

[9] J. Han, D. Farin, P.H.N. de With, W. Lao, "Real-time video content analysis tool for consumer media storage system," IEEE Transactions on Consumer Electronics, vol. 52, no. 3, pp. 870-878, Aug. 2006.

[10] Silvia Ferrando, Gianluca Gera, Massimo Massa,Carlo Regazzoni "A new method for real time abandoned object detection and owner tracking”, Image Processing, IEEE International Conference on Digital Object Identifier, 2006 